\title{
Removal Turbidity of Water by Application of Electromagnetic Field Technology
}

\author{
Maryam Jawad Abdulhasan ${ }^{1 *}$, Nassrin Jassim Hussien Al-Mansori ${ }^{2}$, Mohsin J. Nasir ${ }^{3}$ \\ 1 Chemical Engineering and Petroleum Industries Department, Al-Mustaqbal University College, Babylon, Iraq \\ 2 Environmental Engineering Department, Engineering College, Babylon University, Babylon, Iraq \\ ${ }_{3}^{3}$ Al-Mussaib Technical Institute, Al-Furat Al-Awsat Technical University, 51009 Babylon, Iraq \\ * Corresponding author's e-mail: maryam.jawad@mustaqbal-college.edu.iq
}

\begin{abstract}
Human and which serves to preserve the resource at the science forefront. Water of electromagnetic is old but addressed to popular the quantity of contaminants in a new way. The current study presents results related to the influence of an electromagnetic field (EMF) on synthetic water with $\mathrm{Al}_{2} \mathrm{Si}_{2} \mathrm{O}_{5}(\mathrm{OH})_{4}$ (represented by Turbidity). The impact of an EMF as the only factor or as an intensifying element in stainless steel packing systems that limits pollutant concentrations in the treated water was analyses. The system that combined simultaneously stainless steel filling was most efficient. The electromagnetic treatment unit was designed and constructed for testing the treatment of syntheses water having turbidity. The influence of two variables on the efficiency of contaminant elimination during the function of the electromagnetic treating unit was checked. A significant dependence between the kind of system used reactor diameter and number of electrical coil windings were observed. The results showed that the PH values remain constant with EMF. The performance of the unit is determined by turbidity, the result shows greatest efficiency removal with $99.99 \%$ at the minimum diameter $(2.54 \mathrm{~cm}), 99.99 \%$ in three reactors with three different numbers of coil turns.
\end{abstract}

Keywords: Electromagnetic field, water treatment, steel filling, turbidity removal.

\section{INTRODUCTION}

Worldwide water supplies face drastic changes as a result of rising water demands, global climate change, population development, urbanization and industrialization, and clean drinking water is one of the developing world's most pressing commodities (Abedin et al., 2020). The treatment of such pollutants in conventional plants requires the addition of chemicals that leave residues to be treated. Therefore, today the science has headed to establish a safe, environment friendly and economical treatment unit, it is electromagnetic treatment unit. The treatment of magnetic water is a water process that does not require any filtration and chemical substitutes. The scientific explanation of the treatment of magnetic water has been the subject of examination by many researchers (Wahid et al. 2001). Electromagnetic
Fields (EMFs) demonstrate promising potential for treatments of wastewater and water. Health, flexibility and usability, eco-friendliness, unproven harmful effects and low operating costs are EMFs' key advantages over traditional wastewater treatment methods (Yadollahpour et al., 2014). This research reviews electromagnetic field applications, particularly in treatment of polluted water to improve treatment systems or processes. Since decades, magnetic field applications have been recognized (Basset, 1993; Colic and Morse 1999). The concept of induction was introduced by Michael Faraday as early as 1830, stating that electrical current is caused when a flux of magnetic field is crossed by flow ions or conductive material. Although applications of magnetic field were quickly pursued to show Faraday's claim, worldwide attention was lacking from industrialists and researchers (Shepard 
et al., 1995; Zaidi et al., 2014). The actual birth of contemporary magnetism occurred in 1819 , when Hans found that when the two were placed near each other, a compass needle was deflected perpendicular to a current bearing wire. It was here that electromagnetism was born (Goldman, 2006; Ghernaout, 2018).

The two main goals of this research are first to investigate the possibility of the electromagnetic field from removing turbidity and secondly to choose the optimal design for the electromagnetic treatment system in terms of testing the influence of two variables on the efficiency of the EMTU work.

\section{EXPERIMENTAL PROCEDURES}

The experiment arrangement is as shown in the Figure 1, it consists of five different electromagnetic reactors (pipes) made of PVC material, each reactor consist of solenoid (electrical coil) made up of copper wire having ( $25 \Omega$ resistance), according to the law of the Ampere a magnetized field will be formed around it when the electricity passes through a wire (Rao and Omprakash, 2013). Characteristics for each reactor described in Table 1 . In this research the continuous flow system was adopted.
The reactors are placed vertically to allow all the lines of magnetic field to move through the water and air phases and therefore the EMF can be added without any losses (Choudhari and Patel, 2018). Direct cooling was used to cool the electromagnetic processing unit. Actual reactor length (treatment area inside the reactor) $100 \mathrm{~cm}$ divided 5 parts, the faucets were mounted from the other tap after every $20 \mathrm{~cm}$ (to obtain different level of treatment depending on contact time of water samples with electromagnetic field). From this research (Wahid et al., 2001) found that a magnetic overflow intensity of 670 Gauss ( 0.067 Tesla) can achieve the efficiency of pollutant removal, so in this research it was adopted as a higher value and from that the number of turns around each tube was calculated. The air core was initially used to strengthen the magnetic field within the reactor, the results were not positive due to there was no significant change in the water characteristics. The treating efficiency of water was further improved by the installation of stainless steel strips inside the electromagnetic reactor and along the reactor. Tap water and pure clay (kaolinite) were used to produce synthetically turbid water.

The first stage is to investigate the influence of the field of electromagnetic on the $\mathrm{PH}$ value by

Table 1. The characteristics of each pipe

\begin{tabular}{|c|c|c|c|}
\hline Number of pipe & Diameter $(\mathrm{cm})$ & Number of winding (turn) & Length of reactor (cm) \\
\hline 1 & 2.54 & 3500 & 100 \\
\hline 2 & 2.54 & 4000 & 100 \\
\hline 3 & 2.54 & 4500 & 100 \\
\hline 4 & 3.81 & 4500 & 100 \\
\hline 5 & 5.08 & 4500 & 100 \\
\hline
\end{tabular}

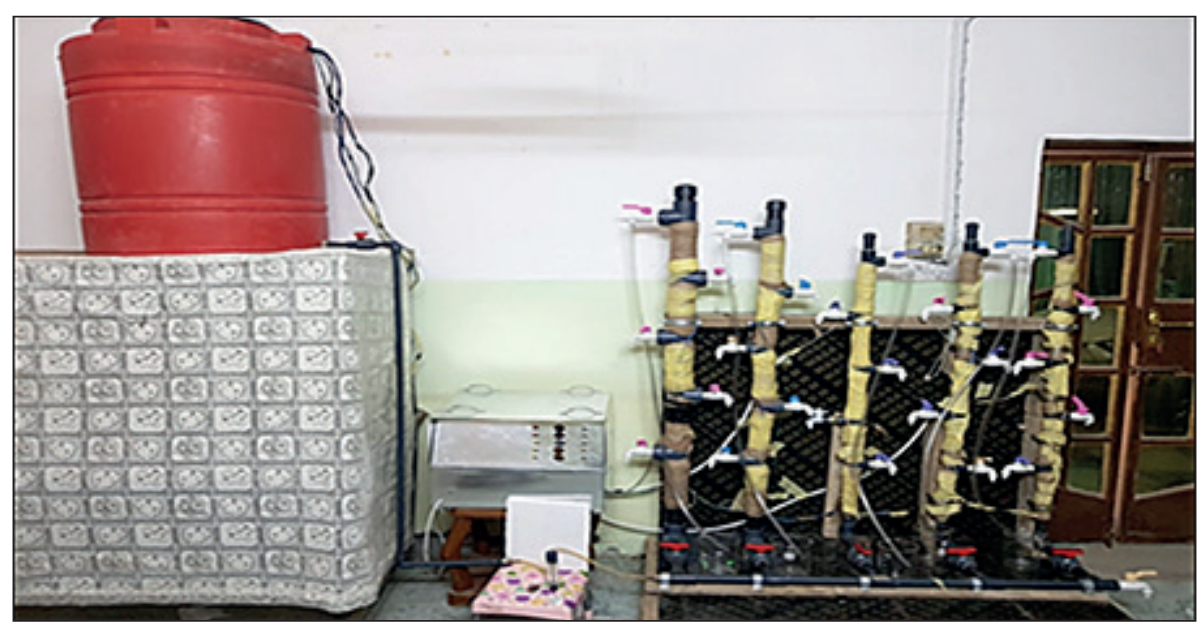

Figure 1. Electromagnetic treatment unit 
exposing the water sample to three different intensities of the electromagnetic field $(4320,6000$, and $8000)$ guesses. In the second stage of the examination, the possibility of removing the turbidity of synthesis water after its contamination with kaolinite clay was examined. The arrangement of electromagnetic experiment is as shown in Figure 1.

\section{RESULTS}

After passing water through the electromagnetic field for 1, 2,3,4,5 hours the first stage of research was conducted to demonstrate the effect of electromagnetically treating general drain water. This test was performed on three EM intensities $(4320,6000$, and 8000$)$ guesses of treated water. The results obtained showed no significant change in the PH value as shown in Table 2.
In the second stage of the experiment the kaolinite clay was added to the tap water. The experiment results showed that the electromagnetic field is capable of removing turbidity with excellent efficiency. Turbidity removal rates ranging from the highest removal rate to $99.99 \%$ in three reactors with three different numbers of coils turns as shown in Table 3. EMTU effectiveness with removing turbidity at smallest reactor diameter, removal efficiency equal to $(93.8,99.82$ and 99.99$)$ percent at $(5.08,3.81$ and 2.54) $\mathrm{cm}$ reactor diameter, as in Table 4.

For the second stage, as indicated from experiments, the removal efficiency of turbidity for the reactor No.3, 4500 turns, is much better than for the reactor No.1, 3500 turns. Where a clearance efficiency of $99.99 \%$ was obtained after the third hour of starting treatment in reactor No. 3, while the same ratio was obtained in reactor No. 1 and 2 after the fourth and fifth hours of starting treatment. Thus, the number of coil turns can be

Table 2. $\mathrm{PH}$ value after exposing to different three electromagnetic intensities.

\begin{tabular}{|c|c|c|c|c|}
\hline Sample & Time (hours) & $\mathrm{PH}$ at intensity of 4320 Gusses & $\mathrm{PH}$ at intensity of 6000 Gusses & $\mathrm{PH}$ at intensity of 8000 Gusses \\
\hline a & 0 & 7.1 & 7.1 & 7.1 \\
\hline $\mathrm{b}$ & 1 & 7.1 & 7.0 & 7.1 \\
\hline c & 2 & 7 & 7.1 & 7.1 \\
\hline $\mathrm{d}$ & 3 & 7 & 7.1 & 7.2 \\
\hline e & 4 & 7.1 & 7.1 & 7.1 \\
\hline f & 5 & 7.1 & 7.2 & 7.1 \\
\hline
\end{tabular}

Table 3. Changing of turbidity concentration after exposing to EMF with different number of electrical coil

\begin{tabular}{|c|c|c|c|c|}
\hline Sample & Time (hours) & $\begin{array}{c}\text { Turbidity value (NTU) } \\
\text { at 3500 turn }\end{array}$ & $\begin{array}{c}\text { Turbidity value (NTU) } \\
\text { at 4000 turn }\end{array}$ & $\begin{array}{c}\text { Turbidity value (NTU) } \\
\text { at 4500 turn }\end{array}$ \\
\hline A & 0 & 50 & 50 & 50 \\
\hline B & 1 & 37.1 & 47.1 & 31.4 \\
\hline C & 2 & 14.1 & 31.7 & 25.6 \\
\hline D & 3 & 5.7 & 14.2 & 7.64 \\
\hline E & 4 & 0.1 & 3 & 3.44 \\
\hline F & 5 & 0.0001 & 0.01 & 0.00002 \\
\hline
\end{tabular}

Table 4. Changing of turbidity concentration after exposing to EMF with different reactor diameter

\begin{tabular}{|c|c|c|c|c|}
\hline Sample & Time (hours) & $\begin{array}{c}\text { Turbidity value (NTU) } \\
\text { at diameter }=2.45 \mathrm{~cm}\end{array}$ & $\begin{array}{c}\text { Turbidity value (NTU) } \\
\text { at diameter }=3.81 \mathrm{~cm}\end{array}$ & $\begin{array}{c}\text { Turbidity value (NTU) } \\
\text { at diameter }=5.08 \mathrm{~cm}\end{array}$ \\
\hline A & 0 & 50 & 50 & 50 \\
\hline B & 1 & 31.4 & 21.9 & 45.7 \\
\hline C & 2 & 25.6 & 11 & 33 \\
\hline D & 3 & 7.64 & 5.22 & 22.4 \\
\hline E & 4 & 3.44 & 3.36 & 11.7 \\
\hline F & 5 & 0.00002 & 0.09 & 3.1 \\
\hline
\end{tabular}


increased and the processing time reduced to save the energy used. Through the results of the previous three tests, it became clear that increasing the diameter of the reactor reduces the efficiency of removing the pollutant, but during the turbidity test showed this result after the second and third hours of the treatment process. The following is summarized of the three preceding tests, that the turbidity value in synthesis water decreases as the flow rate decreases to increase the time of exposure of the magnetic field to water.

The researcher (Ni'am et al., 2006) proved that the magnetic field has the ability to remove turbidity, as it conducted an experiment to remove turbidity from the waste water. Turbidity removals with the combined process were as high as $92.3 \%$ and $81.25 \%$, while the process of EC was as high as $89.3 \%$ and $75.16 \%$.

\section{CONCLUSIONS}

Using the stainless steel filling in the system of technological effect on higher contaminants reduction in the water. Electromagnetic fieldcaused phenomena favorably affect water treatment. The $\mathrm{pH}$ value remains constant, unaffected by the electromagnetic field, even after five hours of exposure to three degrees of treatment (4320, $6000,8000)$ Guesses with the electromagnetic field. The electromagnetic processing unit is more efficient for removing turbidity when increasing the number of coil turns. The electromagnetic processing unit is more effective to eliminate turbidity when the diameter of the reactor decreases.

Dear future researcher, here are some recommendations for future research in the field of electromagnetic water treatment unit. Solar energy can be used instead of usual electrical generating to make the EMTU more economical. The future researcher must test the efficiency of removing total dissolved solids.

\section{REFERENCES}

1. Abedin M.A., Ray B., Kibria M.G., Shaw R. 2020. Smart water solutions to address salinity, Drinking water and health issues in coastal Bangladesh. In public health and disasters Springer, Singapore, 129-143.

2. Basset C.A.L. 1993. Therapeutic uses of electric and magnetic fields inorthopaedics. In Biological Effects of Electric and Magnetic Fields; Carpenter, D., ed.; Academic Press: New York.

3. Choudhari S. and Patel B. 2018. Influence on effluent characteristics under electromagnetic field (EMF), 450.

4. Colic M. and Morse D. 1999. The elusive mechanism of the magnetic 'memory' of water. Coll. Surf., A., 154(1-2), 167-174.

5. Ghernaout D. 2018. Magnetic field generation in the water treatment perspectives: An overview. Int. J. Adv. Appl. Sci, 5, 193-203.

6. McMahon C.A. 2009. Investigation of the quality of water treated by magnetic fields.

7. Ni'am M.F., Othman F., Sohaili J., Fauzia Z. 2006. Combined magnetic field and electrocoagulation process for suspended solid removal from wastewater. In Proc. 1st International Conference on Natural Resources Engineering and Technology, Putrajaya, Malaysia, 384-393.

8. Rao M.S. and Omprakash S. 2013. Study of electromagnetic waves on industrial waste water. Physics and Materials Chemistry, 1(3), 34-40.

9. Shepard D.P., Edling B., Reimers R. 1995. Magnetic water treatment.GolfCourse Management, 63(3), 55-58.

10. Yadollahpour A., Rashidi S., Ghotbeddin Z., Jalilifar M., Rezaee Z. 2014. Electromagnetic fields for the treatments of wastewater: a review of applications and future opportunities. J Pure Appl Microbio, 8(5), 3711-19.

11. Zaidi N.S., Sohaili J., Muda K., Sillanpää M. 2014. Magnetic field application and its potential in water and wastewater treatment systems. Separation \& Purification Reviews, 43(3), 206-240. 